Article

\title{
A Hyaluronic Acid Based Injectable Hydrogel Formed via Photo-Crosslinking Reaction and Thermal-Induced Diels-Alder Reaction for Cartilage Tissue Engineering
}

\author{
Gang Wang ${ }^{1,2}$, Xiaodong Cao ${ }^{1,2,3, *}$, Hua Dong ${ }^{1,2,3}$, Lei Zeng ${ }^{1,2}$, Chenxi $\mathrm{Yu}^{1,2}$ and \\ Xiaofeng Chen ${ }^{1,2,3, *}$ \\ 1 Department of Biomedical Engineering, School of Materials Science and Engineering, South China \\ University of Technology, Guangzhou 510641, China; wanggang_scut@foxmail.com (G.W.); \\ donghua@scut.edu.cn (H.D.); happy-zl@163.com (L.Z.); eric.eu@foxmail.com (C.Y.) \\ 2 National Engineering Research Center for Tissue Restoration and Reconstruction, Guangzhou 510006, China \\ 3 Key Laboratory of Biomedical Materials and Engineering, Ministry of Education, South China University of \\ Technology, Guangzhou 510006, China \\ * Correspondence: caoxd@scut.edu.cn (Xd.C.); chenxf@scut.edu.cn (Xf.C.); Tel.: +86-20-2223-6066 (Xd.C.)
}

Received: 10 June 2018; Accepted: 18 August 2018; Published: 27 August 2018

check for updates

\begin{abstract}
A hyaluronic acid (HA) based injectable hydrogel with gradually increasing mechanical properties was synthesized via photo-crosslinking reaction and thermal-induced Diels-Alder (DA) reaction. The injectable hydrogel can quickly gelate within $30 \mathrm{~s}$ by photo-crosslinking of HA-furan under the catalysis of lithium phenyl-2,4,6-trimethylbenzoylphosphinate (LAP). This injectable property is beneficial to keep the encapsulated cell activity and convenient for clinical operation. And the mechanical properties can be control from 4.86 to $10.66 \mathrm{kPa}$ by exposure time. Then, the thermal-induced DA click chemistry further occurs between furan groups and maleimide groups which gradually promoted the crosslinking density of the injectable hydrogel. The mechanical properties of the injectable hydrogel can be promoted to $21 \mathrm{kPa}$. ATDC- 5 cells were successfully encapsulated in the injectable hydrogel and showed good activity. All the results suggested that the injectable hydrogel with gradually increasing mechanical properties formed by photo-crosslinking reaction and thermal-induced DA reaction has a good prospect of application in cartilage tissue engineering.
\end{abstract}

Keywords: injectable hydrogel; photo-crosslinking reaction; DA click chemistry; cartilage tissue engineering

\section{Introduction}

Due to the lack of blood vessels, nerves and lymphoid tissue, articular cartilage is poor at self-repair and regeneration [1-3]. Thus, when the damage occurs, it is difficult for articular cartilage to repair defects by itself. Although numerous clinical treatments, including microfracture of subchondral bone, autologous chondrocyte implantation and osteoarticular transfer system, have been developed to repair articular cartilage defects, none has succeeded in regenerating articular cartilage with long-lasting [4-6]. With the development of regenerative medicine in the past decades, cartilage tissue engineering technique as a promising approach possesses great potential for effectively reconstructing and regenerating cartilage [7-11].

Hydrogel is an excellent candidate scaffold material for applications in cartilage tissue engineering due to its high water content, good viscoelastic and desirable biocompatibility [12,13]. Up to now, 
there are many gelation processes have been reported for formation hydrogel, such as click chemistry reactions [14,15], radical polymerization [16], Schiff base crosslinking [17,18], ionic interaction [19], hydrophobic interaction [20] and hydrogen bonding [21]. Because the advantages of high reaction yield, harmless byproducts, fast reaction kinetics, strong stereoselectivity and mild reaction conditions, the click chemistry reactions have been highly used to construct cell-compatible hydrogels over the last decade [22]. The thermal-induced Diels-Alder (DA) click chemistry reaction as classic click chemistry, which selective [4 +2] cycloaddition between dienes and dienophiles under mild reaction conditions, has been applied to the formation of hydrogels in many studies [23-25]. The hydrogels which formed by thermal-induced DA click chemistry can obtain uniform network structure and have good mechanical properties, that's very essential for cartilage tissue repair. In our previous studies, we reported multifunctional hydrogels with good elasticity, effective spatiotemporal patterning, antibacterial property and tissue adhesive ability based on thermal-induced DA click chemistry [26-31]. Nevertheless, the progress of thermal-induced DA click reaction is too slow at $37^{\circ} \mathrm{C}$, which cause hydrogels' gelation time more than a few hours. The overlong gelation time is not conducive to the survival of cells encapsulated in hydrogels [28,32]. Meanwhile, the slow gel processing does not endow hydrogel with injectable properties. However, the injectable hydrogels are favorable in biomedical applications because their high shapes adaptability and their effective reduction of the loss of the encapsulated cells [33,34]. Usually, injectable hydrogels are formed by chemical cross-linkers [35], temperature-responsive phase transition [36], or enzymatic crosslinking reactions [30]. Most notably, injectable hydrogels formed by photo-crosslinking reactions have attracted more and more attention because the reactions can be easily controlled by UV exposure [37-39]. However, the too short UV exposure time go against to obtain hydrogels with strong mechanical properties and long exposure time is not conducive to the survival of the encapsulated cells. So, it is challenging but very necessary, for cartilage tissue engineering to obtain a hydrogel which gelatinization by short UV exposure time but have good mechanical properties in the same time.

In this study, we formed a hyaluronic acid based hydrogel (HA/PEG) via photo-crosslinking reaction and thermal-induced DA click chemistry reaction. The HA/PEG hydrogel can quickly gelate within $30 \mathrm{~s}$ by photo-crosslinking reaction of HA-Furan under the catalysis of LAP, the injectable property is beneficial to keep the encapsulated cell activity and also convenient for clinical operation. Then, thermal-induced DA click chemistry further occurred at $37^{\circ} \mathrm{C}$ between furan groups and maleimide groups and the slow reaction gradually increased the mechanical properties of hydrogel. In addition, due to its good cytocompatibility, the HA/PEG hydrogel has great potential for biomedical hydrogel systems. The above characteristics make us believe that the double-crosslinking HA/PEG hydrogels can be used in cell delivery system for cartilage repair.

\section{Materials and Methods}

2,4,6-Trimethylbenzoyl chloride (TMBC) was purchased from Adamas Reagent Co., Ltd. (Shanghai, China), Dimethyl phenylphosphonite (DMPP) (98\%) was purchased from Alfa Aesar (China) Chemical Co., Ltd. (Shanghai, China) Lithium bromide ( $\mathrm{LiBr}$ ) $(99 \%)$ was purchased from Shanghai Aladdin Bio-Chem Technology Co., Ltd. (Shanghai, China). 2-Butanone was purchased from Hunan Hengyang Kaixin Chemical Co., Ltd. (Hengyang, China), 2-morpholinoethane sulfonic acid (MES), 4-(4,6-dimethoxy-1,3,5-triazin-2-yl)-4-methylmorpholiniumchloride (DMTMM) and 2-furylmethylamine (Furan) were purchased from Sigma-Aldrich (Guangzhou, China). Maleimide was purchased from Shanghai Macklin Biochemical Co., Ltd. (Shanghai, China). Hyaluronic acid sodium (HA, $M_{w}=1 \times 10^{6} \mathrm{~g} / \mathrm{mol}$ ) was purchased from Shanghai Crystal Pure Industrial Co., Ltd. (Shanghai, China). Dimaleimide poly(ethylene glycol) (Mal-PEG-Mal) $\left(M_{w}=2 \times 10^{3}\right)$ was purchased from Shanghai Sunway Pharmaceutical Technology Co., Ltd. (Shanghai, China). Dulbecco's Modified Eagle's Medium (DMEM) (4.5 g/L D-Glucose), Fetal bovine serum (FBS), 0.25\% Trypsin-EDTA (1X), Phosphate Buffer Saline (PBS) ( $\mathrm{pH}=7.4$ ) and Penicillin Streptomycin (PS) were purchased from Gibco (Grand Island, NY, USA). Other reagents and solvents were of analytical grade and used as received. 


\subsection{Synthesis of LAP}

The lithium phenyl-2,4,6-trimethylbenzoylphosphinate (LAP), with good water solubility, polymerization rates and cell survival was prepared as originally described by Majima et al. (Scheme 1). [40]. Briefly, $3.2 \mathrm{~g}$ TMBC (0.018 mol) was slowly added to continuously stirred $3.0 \mathrm{~g}$ DMPP $(0.018 \mathrm{~mol})$. Then, under nitrogen atmosphere at room temperature, the mixture was stirred for $24 \mathrm{~h}$. Thereafter, $\mathrm{LiBr}(6.1 \mathrm{~g}, 0.07 \mathrm{~mol})$, dissolved in 2-butanone $(100 \mathrm{~mL})$, was added to the reaction and, subsequently, the temperature was heated to $50{ }^{\circ} \mathrm{C}$. After the reaction duration of $10 \mathrm{~min}$, the reaction was cooled to room temperature and placed for another $4 \mathrm{~h}$. Subsequently, the solid precipitate in the mixture was filtered and washed 3 times with 2-butanone. The solid precipitate (LAP) was obtained by vacuum drying at room temperature for $24 \mathrm{~h}$. The structure of LAP was analyzed by nuclear magnetic resonance $\left({ }^{1} \mathrm{H}\right.$ NMR) (BRUKER, Karlsruhe, Germany).

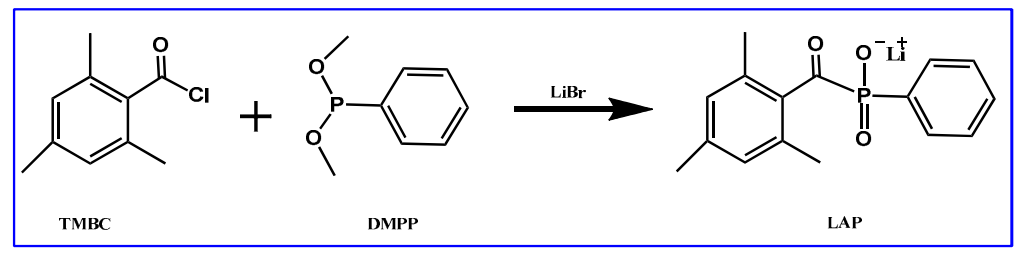

Scheme 1. Synthesis Steps of LAP.

\subsection{Synthesis of HA-Furan}

HA-Furan was obtained according to our previous work (Scheme 2) [28]. In brief, $0.5 \mathrm{~g}$ HA $(1.2 \mathrm{mmol}-\mathrm{COOH})$ was dissolved completely in MES buffer $(250 \mathrm{~mL}, 100 \mathrm{mM})$, then DMTMM $(1.4 \mathrm{~g}$, $5 \mathrm{mmol}$ ) was slowly added to the mixture to activate the carboxyl groups of HA. After stirring for $1 \mathrm{~h}$, Furan $(220 \mu \mathrm{L}, 2.4 \mathrm{mmol})$ was added dropwise and the mixture was stirred and kept at room temperature, avoiding light for $24 \mathrm{~h}$. The reaction product was dialyzed (MWCO: 14,000 Da) against deionized water for three days and additionally lyophilized. Finally, HA-Furan as a white floccule was obtained and the structure was analyzed by ${ }^{1} \mathrm{H}$ NMR (BRUKER, Karlsruhe, Germany).

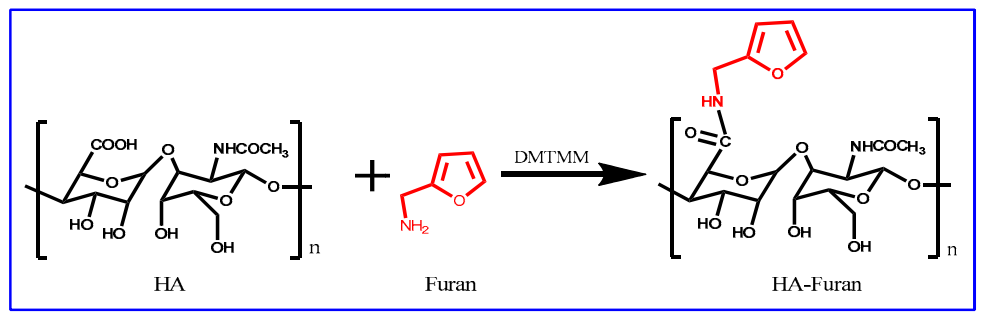

Scheme 2. Synthesis of HA-Furan.

\subsection{Photo-Crosslinking Reaction of HA-Furan with LAP}

The HA-Furan can form gels with the existence of LAP and UV (Scheme 3). The UV-Vis spectrophotometer and ${ }^{1} \mathrm{H}$ NMR were used to investigate the process of photo-crosslinking of HA-Furan under the catalysis of LAP.

In the UV-Vis spectrophotometer test, HA-Furan was dissolved in deionized water to prepare dilute solution with a concentration of $300 \mathrm{mg} / \mathrm{L}$, the solution was tested by ultraviolet visible spectrophotometer (TU-1901, Beijing Purkinje General Instrument Co., Ltd., Beijing, China) after 0 s, $30 \mathrm{~s}, 120 \mathrm{~s}$ and $240 \mathrm{~s}$ of UV irradiation. Similarly, LAP with $15 \mathrm{mg} / \mathrm{L}$ concentration was measured after $0 \mathrm{~s}, 30 \mathrm{~s}$ and $120 \mathrm{~s}$ of UV irradiation. In order to reveal the influence of UV irradiation on HA-Furan with LAP, the solution with HA-Furan $(150 \mathrm{mg} / \mathrm{L})$ and LAP $(15 \mathrm{mg} / \mathrm{L})$ was also tested by ultraviolet visible spectrophotometer Spectra analysis. The scanning range of the wavelength was from 400 to $200 \mathrm{~nm}$. 
In the ${ }^{1} \mathrm{H}$ NMR, the HA-Furan and HA-Furan with LAP under different illumination time were performed on a Bruker AVANCE 400 (Bruker Corporation, Karlsruhe, Germany).

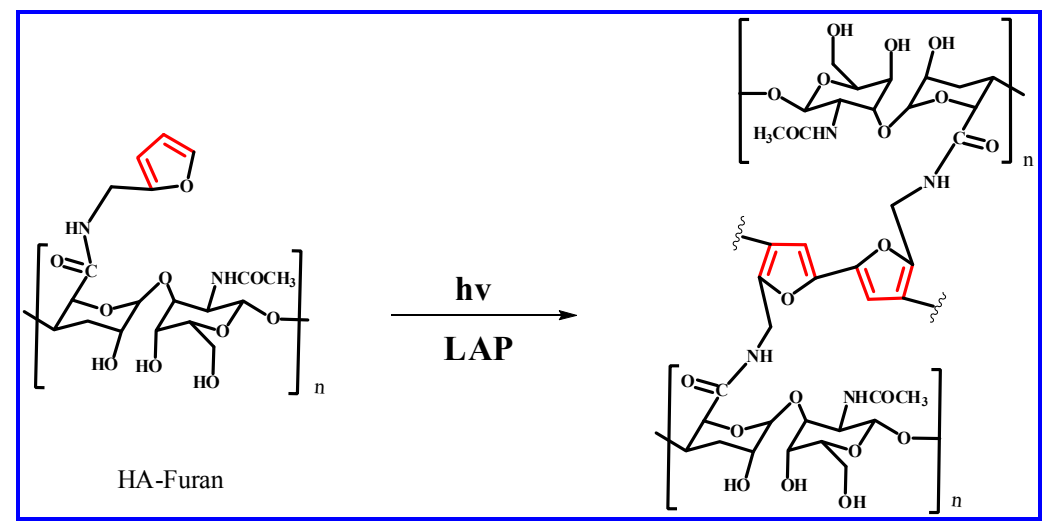

Scheme 3. Photo-crosslinking reaction of HA-Furan with LAP.

\subsection{Dual-Crosslinking Reaction to form HA/PEG Hydrogel}

Lyophilized HA-Furan was totally dissolved at a concentration of $1.5 \% w / v$ in deionized water. The Mal-PEG-Mal solution with concentration of $1 \mathrm{~g} / \mathrm{mL}$ (keep the mole ratio of furyl to maleimide was 1:1) was added into the solution and after stirring for $10 \mathrm{~min}$, the lithium phenyl-2,4,6-trimethylbenzoylphosphin-ate (LAP) was added (the mole ratio of furyl to LAP was controlled at 1:1, 2:1 and 4:1). Then, the mixed solution was injected into a cylindrical mold $(10 \mathrm{~mm}$ diameter). The hydrogel was formed first by way of a photo-crosslinking reaction $\left(30 \mathrm{~mW} / \mathrm{cm}^{2}\right.$ at $365 \mathrm{~nm}$ ). Then, as the second crosslinking process, the thermal-induced DA click chemistry will gradually occur at $37^{\circ} \mathrm{C}$ for 1 day. The schematic diagram of dual-crosslinking reaction to form HA/PEG hydrogel was shown in Scheme 4.

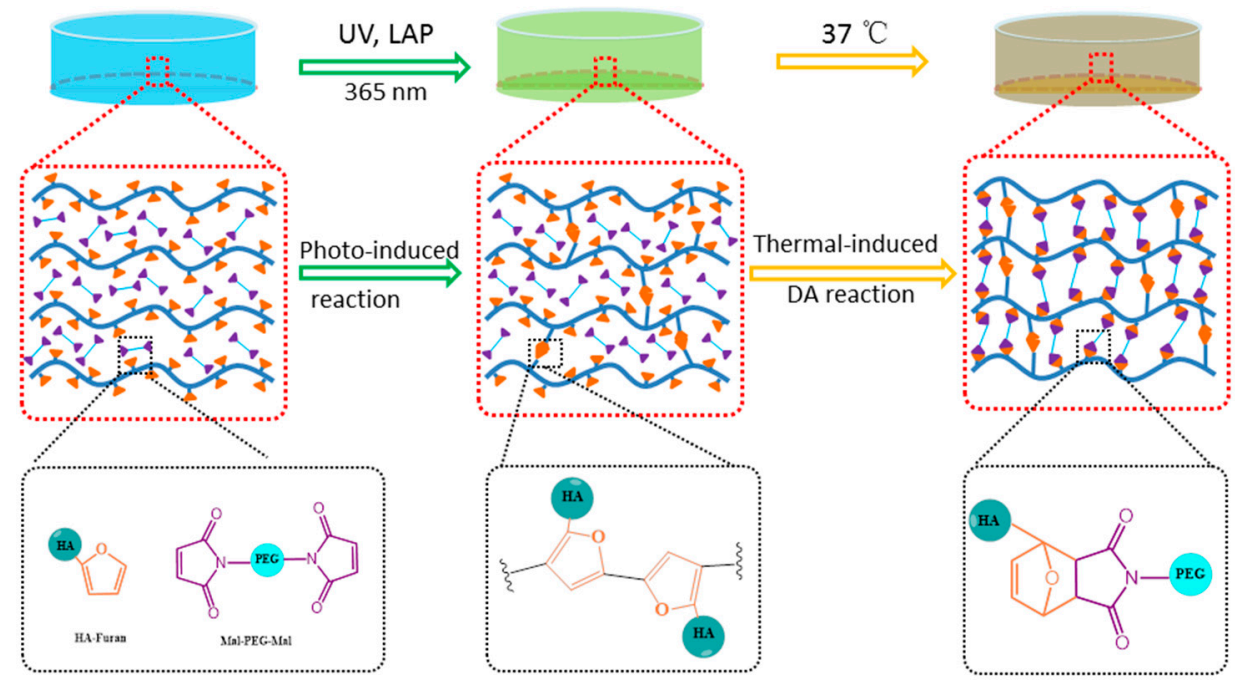

Scheme 4. Schematic diagram of dual-crosslinking reaction to form HA/PEG hydrogel. The first step is photo-crosslinking reaction of HA-Furan under the catalysis of LAP. The second step is the thermal-induced DA reaction between Furan and Mal groups.

\subsection{The Morphology and Gelation Time of HA/PEG Hydrogel}

The scanning electron microscope (SEM) (Quanta 200, FEI, Hillsboro, OR, USA) was employed to observe the morphology of the freeze-dried HA/PEG hydrogels. Before the SEM studies, 
the hydrogel samples were immersed in the deionized water to reach the equilibrated swelling. Then, the samples were placed in $-20{ }^{\circ} \mathrm{C}$ refrigerator for 1 day. The samples were freeze-dried for $48 \mathrm{~h}$. Finally, the freeze-dried samples were coated with gold in SEM coating equipment (Q 150T, Quorum Technologies Ltd., Laughton, East Sussex, UK) for $60 \mathrm{~s}$ for the following SEM studies.

The gelation time of the HA/PEG hydrogels were obtained using a test tube inverting method as mentioned in our previous work [28].

\subsection{Water Absorption of HA/PEG Hydrogel}

The HA/PEG hydrogels were prepared to cylinder ( $5 \mathrm{~mm}$ and diameter $10 \mathrm{~mm}$ ) and were immersed in deionized water at room temperature until reached the equilibrium of swelling. Then, the sample was taken out from deionized water. The surface water was wiped rapidly with filter paper.

The equilibrium swelling ratio (ESR) can be calculated by the below equation:

$$
\mathrm{ESR}=\frac{W_{s}-W_{d}}{W_{d}}
$$

where $W_{d}$ and $W_{s}$ are the weights of the hydrogels in a freeze-dried state and an equilibrium swelling state, respectively.

\subsection{Mechanical Testing}

In order to reveal the relationship between dual-crosslinking reaction and mechanical properties of hydrogels, the stress-strain curve was tested under compression by a dynamic mechanical analyzer (DMA Q800, TA Instruments, New Castle, PA, USA) with linear ramp force $1 \mathrm{~N} / \mathrm{min}$. The hydrogel samples were prepared in cylinders with a height of $5 \mathrm{~mm}$ and a diameter of $10 \mathrm{~mm}$.

\subsection{Cells Encapsulation in the HA/PEG Hydrogel}

Derived from mouse teratocarcinoma cells, the murine chondrocyte ATDC-5 cell line is used as a chondrogenic cell line in some studies [41]. Thus, it was chosen for encapsulation into the double-crosslinking hydrogel (HA/PEG). ATDC-5 cells were planted into the culture medium consisted of $89 \%$ DMEM, 10\% FBS and 1\% PS and expanded for $4-5$ days in incubator with $37{ }^{\circ} \mathrm{C}$ and $5 \% \mathrm{CO}_{2}$, the medium was updated every other day. In order to encapsulate the ATDC-5 cells, the cells were detached using $0.25 \%$ Trypsin-EDTA (1X), resuspended in the culture medium and used for the experiments. Mal-PEG-Mal and LAP solutions were dissolved with PBS and sterilized by filtration through filters with a pore size of $0.22 \mu \mathrm{m}$. HA-Furan powder was sterilized by Co60 irradiation sterilization. The HA-Furan solution was prepared by culture medium. ATDC- 5 cells were encapsulated in the double-crosslinking hydrogels using the same procedure of gel formation. Briefly, the Mal-PEG-Mal $(0.5 \mathrm{~g} / \mathrm{mL}, 1 \mathrm{~mL}$, keep the molar ratio of furan to maleimide 1:1) was first added into the $2 \mathrm{~mL}$ HA-Furan $(1.5 \% \mathrm{w} / \mathrm{v})$ solution and stirred for $10 \mathrm{~min}$. Then, the suspended ATDC-5 cells $\left(2 \mathrm{~mL}, 1 \times 10^{7}\right.$ cells per $\left.\mathrm{mL}\right)$ and LAP $(5 \%, 40 \mu \mathrm{L})$ were added in order. The mixed solution was injected into a cylindrical mold (10 $\mathrm{mm}$ diameter). The live-dead assay was used to study the cells viability encapsulated in the double-crosslinking hydrogels.

\section{Results and Discussion}

\subsection{Chemical Structure of LAP}

Following synthesis of the LAP (Scheme 1), ${ }^{1} \mathrm{H}$ NMR was adopted to verify the structure of the LAP (Figure 1). From the Figure 1, we can observe the Peaks consistent with the proposed structure: ${ }^{1} \mathrm{H}$ NMR $\left(500 \mathrm{MHz}, \mathrm{D}_{2} \mathrm{O}\right): 7.57(\mathrm{~m}, 2 \mathrm{H}), 7.41(\mathrm{~m}, 1 \mathrm{H}), 7.34(\mathrm{~m}, 2 \mathrm{H}), 6.75(\mathrm{~s}, 2 \mathrm{H}), 2.09(\mathrm{~s}, 3 \mathrm{H}), 1.89(\mathrm{~s}, 6 \mathrm{H})$. The result showed that the LAP was successfully synthesized. 


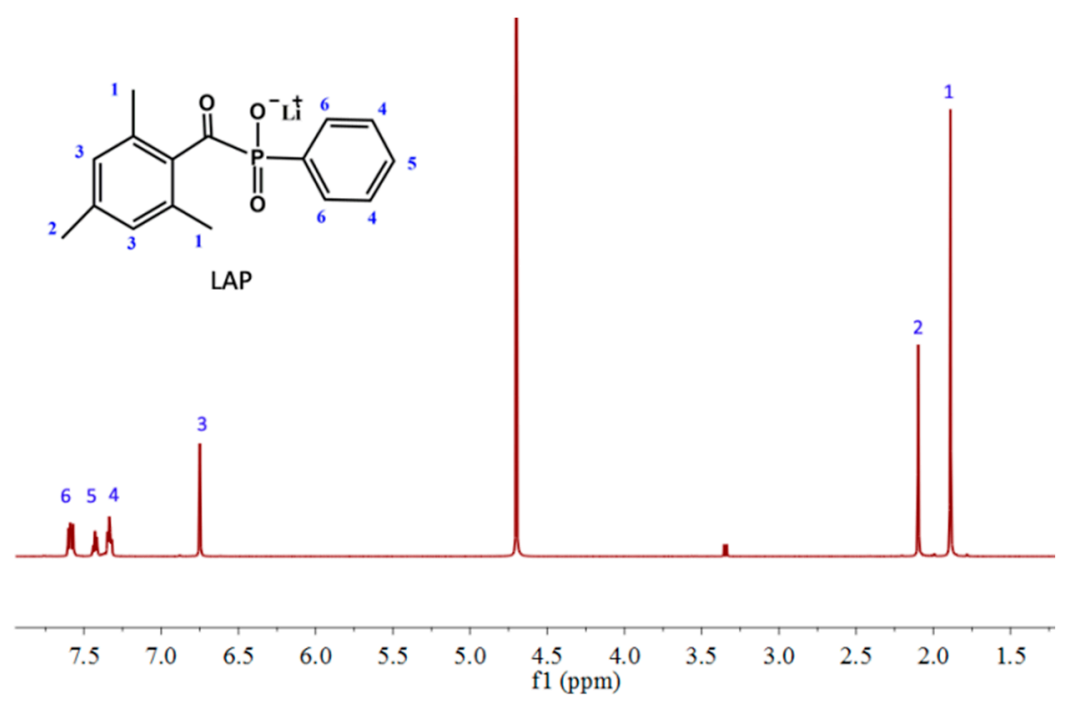

Figure 1. ${ }^{1} \mathrm{H}$ NMR spectra in $\mathrm{D}_{2} \mathrm{O}(400 \mathrm{MHz})$ of LAP showed that LAP had been successfully synthesized.

\subsection{Chemical Structure of HA-Furan}

The HA-Furan was obtained by binding furfurylamine to HA using DMTMM regent (Scheme 2). The chemical structure of HA-Furan was confirmed by ${ }^{1} \mathrm{H}$ NMR (Figure 2). The peaks at 6.28, 6.33 and $7.39 \mathrm{ppm}$ refer to the protons of Furan, those peaks showed that the Furan group was successfully grafted to HA. The integral ratio on the ${ }^{1} \mathrm{H}$ NMR spectrum suggested that HA was grafted with Furan groups on average $68 \%$. The degree of substitution (DS) of HA-Furan was calculated as follows.

$$
\mathrm{DS}=\frac{\operatorname{area}(6.28 \mathrm{ppm})+\operatorname{area}(6.33 \mathrm{ppm})+\operatorname{area}(7.41 \mathrm{ppm})}{\operatorname{area}(1.89 \mathrm{ppm})}
$$

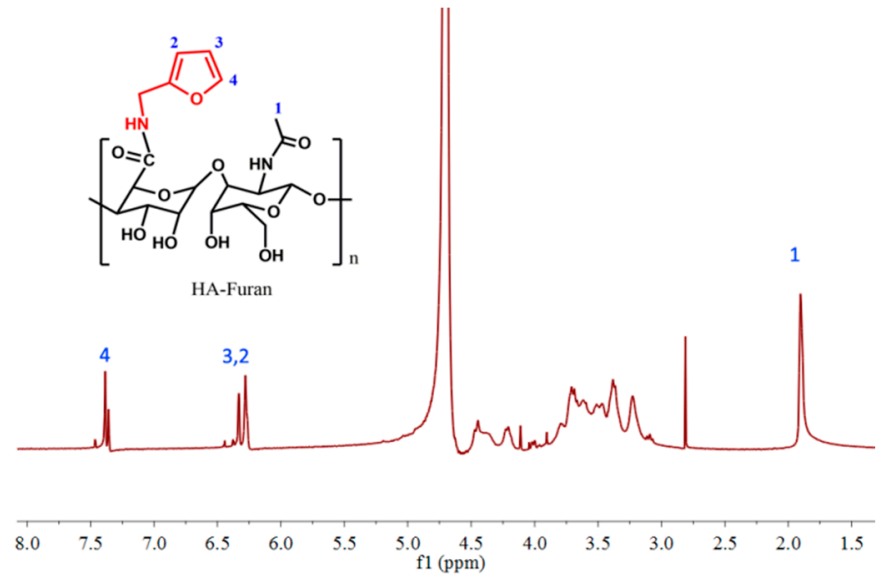

Figure 2. ${ }^{1} \mathrm{H}$ NMR spectra in $\mathrm{D}_{2} \mathrm{O}(400 \mathrm{MHz})$ of HA-Furan.

\subsection{Photo-Crosslinking Reaction of HA-Furan with LAP}

The polymerization of furan has been reported [42-44]. In this study, the UV-Vis spectrophotometer and ${ }^{1} \mathrm{H}$ NMR were adopted to verify the process of photo-crosslinking of HA-Furan under the catalysis of LAP.

As shown in Figure 3A, the absorption peak of $217 \mathrm{~nm}$ was produced by the conjugated groups on the furan group. With the increase of irradiation time, the $217 \mathrm{~nm}$ peaks did not change. This indicated that UV irradiation did not change the conjugated structure of furan group. From Figure 3B, we can see that LAP without UV irradiation has an absorption peak at $205 \mathrm{~nm}$. The blue shift was displayed 
when LAP was irradiated. When the UV irradiation was $120 \mathrm{~s}$, the absorption peak of LAP was even less than $200 \mathrm{~nm}$. Compared with Figure 3A,B, the absorption peak at $217 \mathrm{~nm}$ of the solution without UV irradiation (Figure 3C) was produced by the conjugate structure of the furan group in HA-Furan. The intensity of this peak decreased with the increased of illumination time. Meanwhile, a new band at $275 \mathrm{~nm}$ has appeared in Figure 3C with the increasing of illumination time. The reason for these changes is the increased conjugation structure in the gelatinization process of HA-Furan.
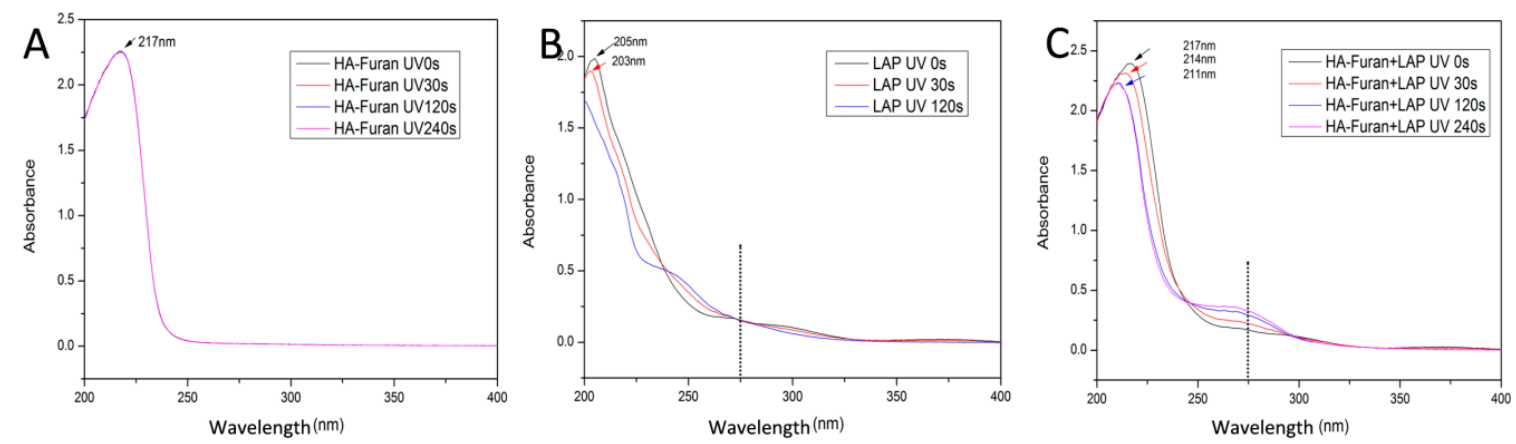

Figure 3. UV-Vis spectrophotometer under different illumination time. (A) HA-Furan; (B) LAP; (C) HA-Furan with LAP.

The ${ }^{1} \mathrm{H}$ NMR of HA-Furan and HA-Furan with LAP under different illumination time was shown in Figure 4. Compared with the hydrogen spectrum without illumination (UV $0 \mathrm{~s}$ ), the signal of the hydrogen spectrum on furan $(\mathrm{a}, \mathrm{b}$ and $\mathrm{c})$ significantly reduced with the illumination time (UV $60 \mathrm{~s}$, $120 \mathrm{~s}$ and $240 \mathrm{~s}$ ). This indicated that the furan group of HA-Furan constantly participated in the process of hydrogel formation with the continuous illumination. Combined with the results of UV-Vis spectrophotometer in Figure 3, we can know that the furan group of HA-Furan took part in the process of hydrogel formation reaction with the existence of LAP and UV but the conjugate double bond of furan was not destroyed and the conjugate effect of the system was enhanced. So, we believe the gelation of HA-Furan is more likely caused by polymerization of furan under the catalysis of LAP as the initiator which was shown in Scheme 3.
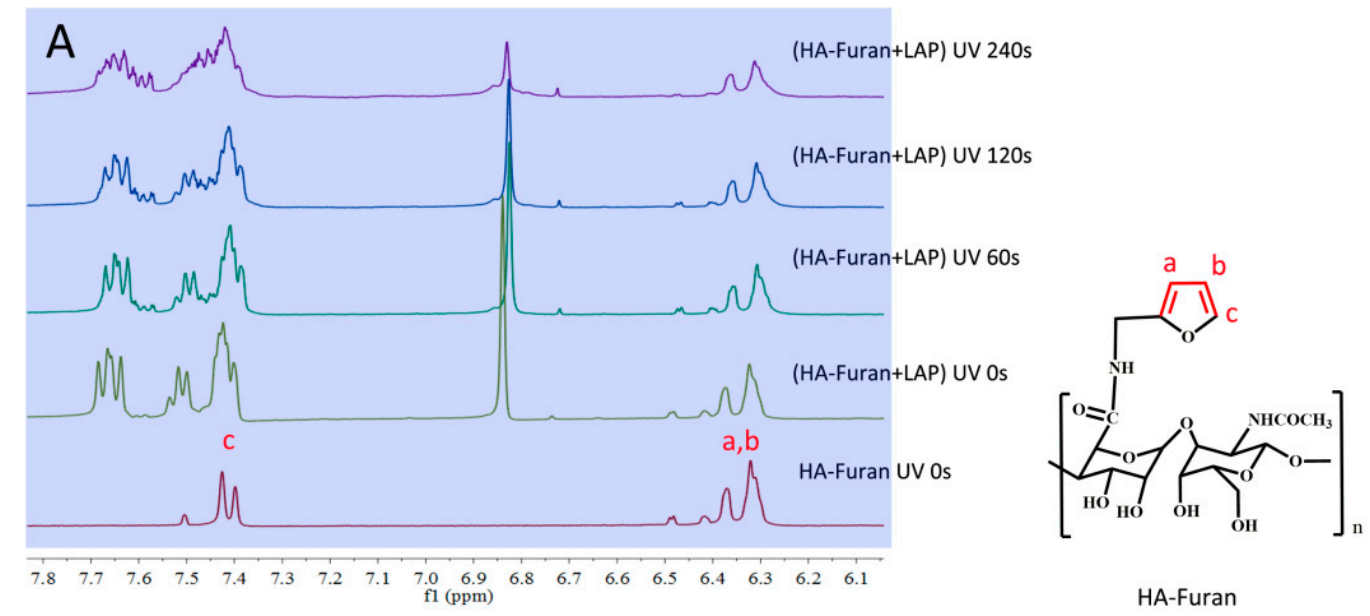

Figure 4. Cont. 


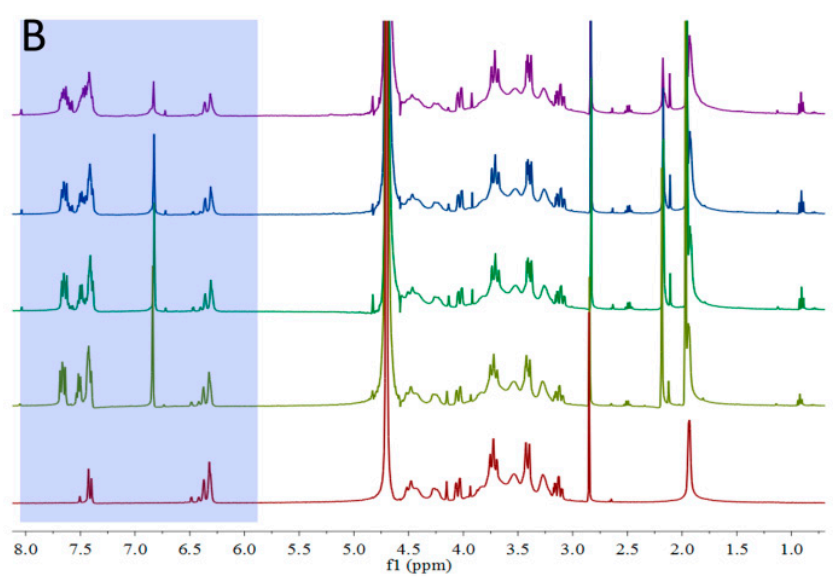

Figure 4. The ${ }^{1} \mathrm{H}$ NMR of HA-Furan with LAP under different illumination time. (A) Chemical shift between $6.1 \mathrm{ppm}$ and $7.8 \mathrm{ppm}$; (B) Chemical shift between $1.0 \mathrm{ppm}$ and $8.0 \mathrm{ppm}$.

\subsection{Gelation Time of Double-Crosslinking Hydrogel (HA/PEG)}

The gelation time (GT) of double-crosslinking hydrogel relied on photo-crosslinking reaction. Table 1 shows the gelation time on the concentration of LAP. Keeping a constant molar ratio of Furan and Mal, the gelation time increased with the decreased LAP concentration (Figure 5 and Table 1). The start gelling time of the HA/PEG can easily control by UV light and the hydrogel can rapid formation within $30 \mathrm{~s}$. This rapid controllable gelation behavior is not only beneficial for cell encapsulation and survival but also beneficial for the operation of the HA/PEG hydrogel in clinics.

Table 1. The gelation time (GT) of HA/PEG hydrogel.

\begin{tabular}{ccc}
\hline Sample & [Furan]:[Mal]:[LAP] & GT (s) \\
\hline HA/PEG-I & $1: 1: 1$ & 20 \\
HA/PEG-II & $2: 2: 1$ & 25 \\
HA/PEG-III & $4: 4: 1$ & 30 \\
\hline
\end{tabular}
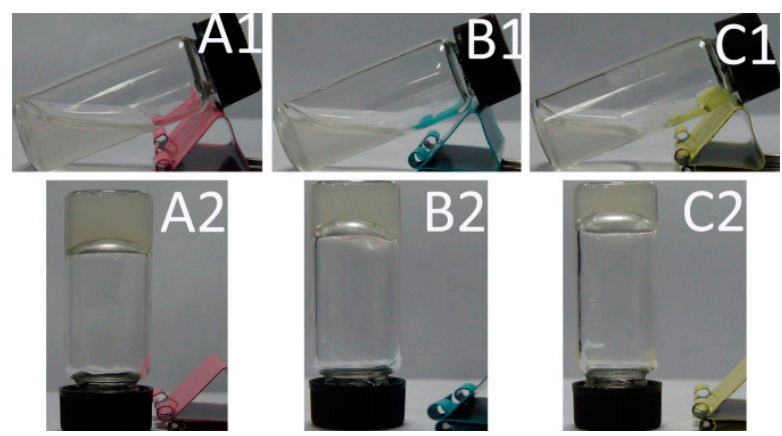

Figure 5. Gelation photos of HA/PEG hydrogels. (A1-C1) were the photos before gelation of HA/ PEG-I, HA/PEG-II, HA/PEG-III, respectively; (A2-C2) were the photos after gelation of HA/PEG-I, HA/PEG-II, HA/PEG-III, respectively.

\subsection{Morphology of HA/PEG Hydrogel}

The relationship between the dual-crosslinking reaction and the network structure can be revealed by the morphology of HA/PEG-III hydrogel (Figure 6). It was found that the pore size of freeze dried hydrogel formed only by photo-crosslinking reaction (Figure 6A, only UV light $30 \mathrm{~s}$ ) is much bigger than that formed by double-crosslinking reaction (Figure 6B, UV $30 \mathrm{~s}$, then $37^{\circ} \mathrm{C}$ further reaction for 
$24 \mathrm{~h}$ ). It is well known that the pore size of hydrogels is attributed to its crosslinking density. Therefore, the dual-crosslinking reaction can increase the crosslinking density of the HA/PEG hydrogel.
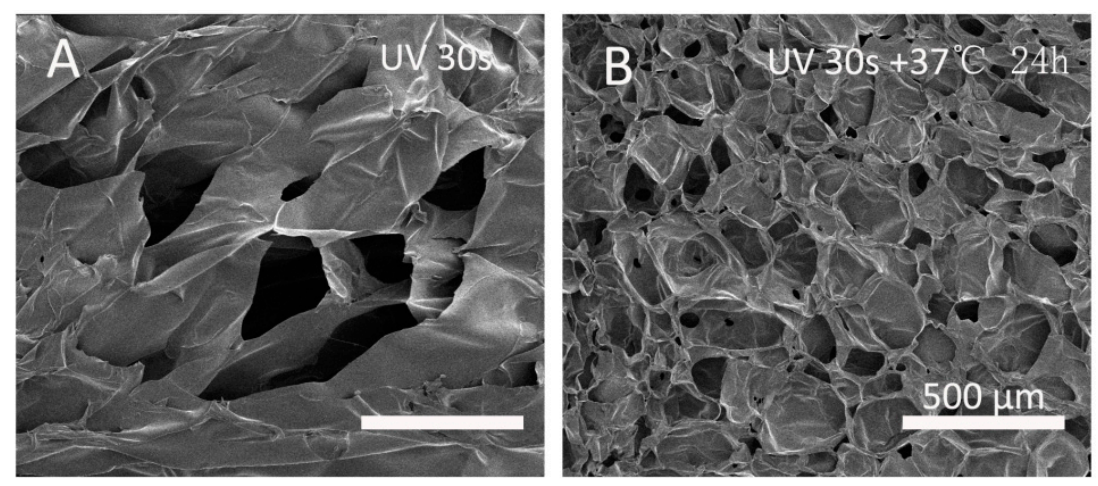

Figure 6. SEM of HA/PEG-III hydrogel formed via photo-crosslinking reaction and thermal-induced DA reaction. (A) only UV light $30 \mathrm{~s}$; (B) UV $30 \mathrm{~S}$, then $37^{\circ} \mathrm{C}$ further reaction for $24 \mathrm{~h}$. Scale bar: $500 \mu \mathrm{m}$.

\subsection{Mechanical Properties of HA/PEG Hydrogel}

In order to reveal the relationship between dual-crosslinking reaction and mechanical properties, HA/PEG-III hydrogel was tested under compression by a dynamic mechanical analyzer (DMA Q800 USA). From the resulting compressive stress-strain plots in Figure 7A, the mechanical properties of the HA/PEG-III hydrogel increased with the increasing of the exposure time from $30 \mathrm{~s}$ to $240 \mathrm{~s}$. That was because the photo-crosslinking reaction was the first crosslinking reaction, the crosslinking density depended the exposure time of UV. Then, the light forming hydrogel was placed under a temperature of $37^{\circ} \mathrm{C}$ for $24 \mathrm{~h}$, the thermal-induced Diels-Alder (DA) click chemistry, as the second crosslinking process, slowly occurred to further improve the crosslinking density of the HA/PEG-III. To our surprise, the mechanical properties of the HA/PEG-III hydrogels with different exposure time tend to be same after placed under $37^{\circ} \mathrm{C}$ for $24 \mathrm{~h}$. This result indicated that the final mechanical properties of the hydrogels depend on the concentration of Furan groups and Mal groups. The compressive modulus of the hydrogels (Figure 7B) was calculated from the stress-strain curves and shown the same trend. Therefore, the injectable HA/PEG hydrogel with rapid gelation (30 s) and gradually increasing mechanical properties can be obtained.
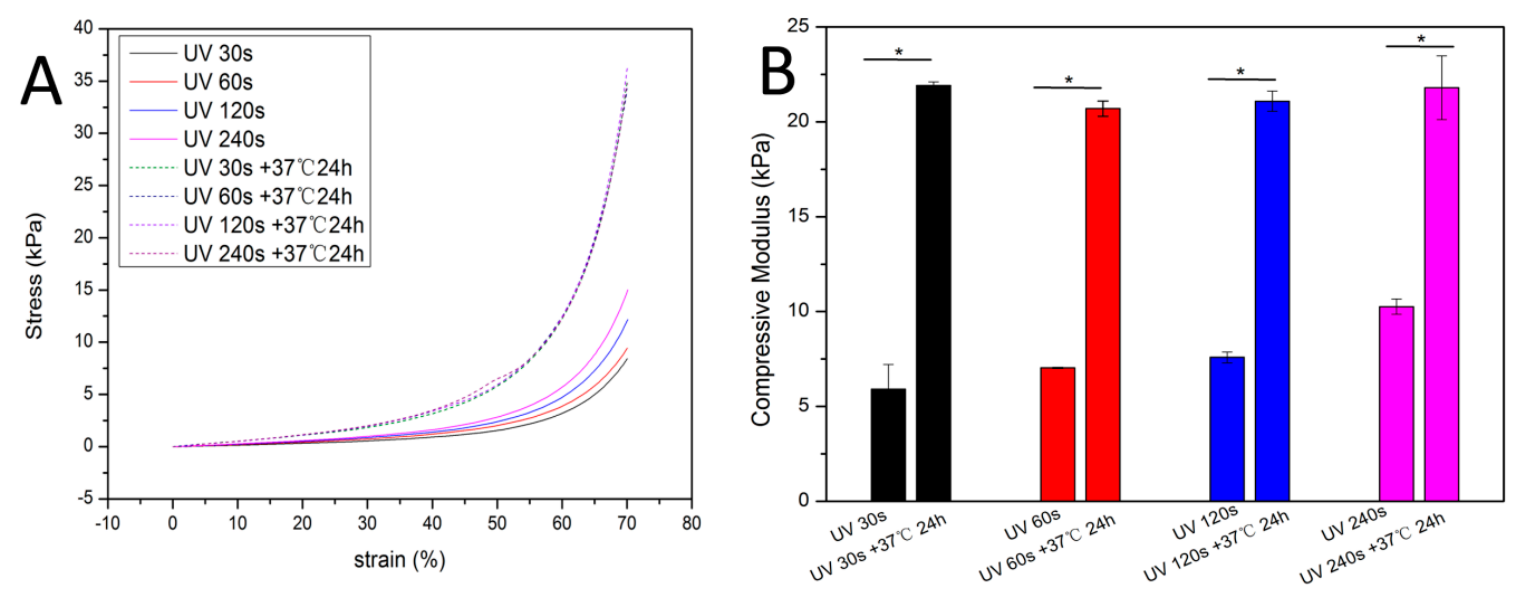

Figure 7. The mechanical properties of HA/PEG-III. (A) Typical compressive stress-strain curves; (B) The compressive modulus of the hydrogels. Error bars represent the SD of measurements performed on 3 samples. 


\subsection{Water Absorption}

The equilibrium swelling ratio (ESR) is a useful parameter for hydrogels, to be used in biomaterials. As shown in Figure 8, the ESR of HA/PEG hydrogel decreased with UV exposure time increased. This behavior could be attributed to further progress of photo-crosslinking reaction along with the increase of exposure time.

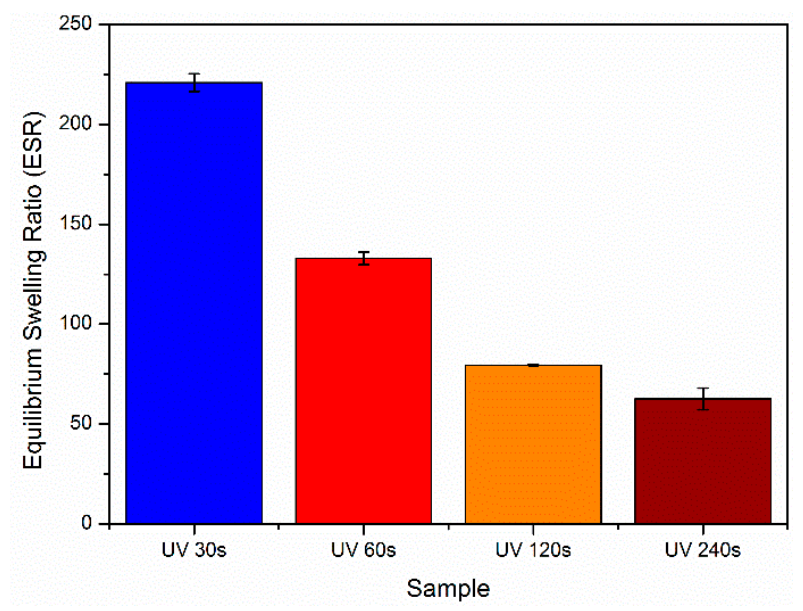

Figure 8. The equilibrium swelling ratio of HA/PEG hydrogels with different UV exposure time. Error bars represent the SD of measurements performed on 4 samples.

\subsection{Cell Viability in the Hydrogel}

The live-dead assay was using to evaluate the viability of encapsulated ATDC- 5 cells in HA/PEG-III hydrogel after cultured 7 days (Living cells and dead cells appearing green and red, respectively). As shown in Figure 9, the high level of cell survival after 7 days culture in hydrogel suggested that the injectable HA/PEG-III hydrogel formed via a photo-crosslinking reaction and thermal-induced DA click chemistry has good cellular compatibility.
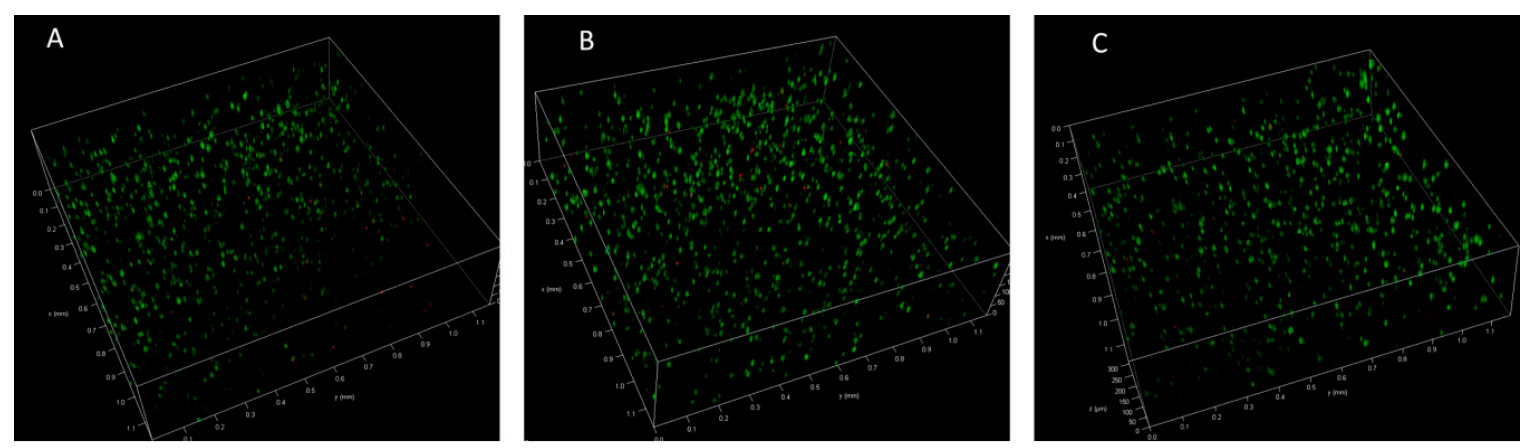

Figure 9. Live-dead assay of encapsulated ATDC-5 cells in HA/PEG hydrogel (A) 1 day; (B) 4 days;

(C) 7 days. (Living cells appearing green and dead cells appearing red).

\section{Conclusions}

A dual-crosslinking reaction that formed HA/PEG hydrogel with injectable properties, gradually increasing mechanical properties and good cell compatibility has been demonstrated in this study. The injectable HA/PEG hydrogel can quickly gelate within $30 \mathrm{~s}$ by way of a photo-crosslinking reaction of HA-Furan with LAP, which is beneficial for keeping the encapsulated cell activity and convenient for clinical operation. The thermal-induced DA click chemistry further slowly occurred between Furan groups and Mal groups, which gradually increased the crosslinking density and 
mechanical properties of the hydrogel. The injectable HA/PEG hydrogel successfully encapsulated the ATDC- 5 cells in situ and showed good cytocompatibility. The above results reveal that the injectable hydrogel with gradually increasing mechanical properties, formed via a photo-crosslinking reaction and thermal-induced DA click chemistry, has great potential applications in cartilage tissue engineering.

Author Contributions: Conceptualization, G.W., X.C. (Xiaodong Cao) and X.C. (Xiaofeng Chen); Methodology, H.D.; Software, L.Z.; Validation, X.C. (Xiaodong Cao) and X.C. (Xiaofeng Chen); Investigation, G.W.; Resources, X.C. (Xiaodong Cao) and X.C. (Xiaofeng Chen); Data Curation, X.C. (Xiaodong Cao) and X.C. (Xiaofeng Chen); Writing-Original Draft Preparation, G.W.; Writing-Review \& Editing, X.C. (Xiaodong Cao) and X.C. (Xiaofeng Chen); Visualization, C.Y.; Project Administration, X.C. (Xiaodong Cao) and X.C. (Xiaofeng Chen).

Funding: This research was funded by National Natural Science Foundation of China (No. 21574045, U1501245, 51672088 ), the Guangzhou Science and Technology Program (No. 201508010060), the Health Care Collaborative Innovation Major Project of Guangzhou (No. 201604020008), the Fundamental Research Funds for the Central Universities (No. 2017ZD003) and the Science and Technology Innovation Team Project of Foshan (No. 2015IT100062).

Conflicts of Interest: The authors declare no conflict of interest.

\section{References}

1. Buckwalter, J.A. Articular Cartilage: Injuries and Potential for Healing. J. Orthop. Sports Phys. Ther. 1998, 28, 192-202. [CrossRef] [PubMed]

2. Sridhar, B.V.; Brock, J.L.; Silver, J.S.; Leight, J.L.; Randolph, M.A.; Anseth, K.S. Development of a cellularly degradable PEG hydrogel to promote articular cartilage extracellular matrix deposition. Adv. Healthc. Mater. 2015, 4, 702-713. [CrossRef] [PubMed]

3. Yuan, T.; Zhang, L.; Li, K.; Fan, H.; Fan, Y.; Liang, J.; Zhang, X. Collagen hydrogel as an immunomodulatory scaffold in cartilage tissue engineering. J. Biomed. Mater. Res. Part B Appl. Biomater. 2014, 102, 337-344. [CrossRef] [PubMed]

4. Mithoefer, K.; Mcadams, T.; Williams, R.J.; Kreuz, P.C.; Mandelbaum, B.R. Clinical efficacy of the microfracture technique for articular cartilage repair in the knee: An evidence-based systematic analysis. Am. J. Sports Med. 2009, 37, 2053-2063. [CrossRef] [PubMed]

5. Johnstone, B.; Alini, M.; Cucchiarini, M.; Dodge, G.; Eglin, D.; Guilak, F.; Madry, H.; Mata, A.; Mauck, R.; Semino, C.; et al. Tissue engineering for articular cartilage repair-The state of the art. Eur. Cells Mater. 2013, 25, 248-267. [CrossRef]

6. Makris, E.A.; Gomoll, A.H.; Malizos, K.N.; Hu, J.C.; Athanasiou, K.A. Repair and tissue engineering techniques for articular cartilage. Nat. Rev. Rheumatol. 2015, 11, 21-34. [CrossRef] [PubMed]

7. Markstedt, K.; Mantas, A.; Tournier, I.; Martínez Ávila, H.; Hägg, D.; Gatenholm, P. 3D bioprinting human chondrocytes with nanocellulose-alginate bioink for cartilage tissue engineering applications. Biomacromolecules 2015, 16, 1489-1496. [CrossRef] [PubMed]

8. Laronda, M.M.; Rutz, A.L.; Xiao, S.; Whelan, K.A.; Duncan, F.E.; Roth, E.W.; Woodruff, T.K.; Shah, R.N. A bioprosthetic ovary created using 3D printed microporous scaffolds restores ovarian function in sterilized mice. Nat. Commun. 2017, 8, 15261. [CrossRef] [PubMed]

9. Xu, T.; Binder, K.W.; Albanna, M.Z.; Dice, D.; Zhao, W.; Yoo, J.J.; Atala, A. Hybrid printing of mechanically and biologically improved constructs for cartilage tissue engineering applications. Biofabrication 2013, 5. [CrossRef] [PubMed]

10. Huey, D.J.; Hu, J.C.; Athanasiou, K.A. Unlike bone, cartilage regeneration remains elusive. Science 2012, 338, 917-921. [CrossRef] [PubMed]

11. Daley, G.Q.; Scadden, D.T. Prospects for Stem Cell-Based Therapy. Cell 2008, 132, 544-548. [CrossRef] [PubMed]

12. Li, Q.; Wang, J.; Shahani, S.; Sun, D.D.N.; Sharma, B.; Elisseeff, J.H.; Leong, K.W. Biodegradable and photocrosslinkable polyphosphoester hydrogel. Biomaterials 2006, 27, 1027-1034. [CrossRef] [PubMed]

13. Yang, K.; Sun, J.; Wei, D.; Yuan, L.; Yang, J.; Guo, L.; Fan, H.; Zhang, X. Photo-crosslinked mono-component type II collagen hydrogel as a matrix to induce chondrogenic differentiation of bone marrow mesenchymal stem cells. J. Mater. Chem. B 2017, 5, 8707-8718. [CrossRef] 
14. Wang, H.; Zha, G.; Du, H.; Gao, L.; Li, X.; Shen, Z.; Zhu, W. Facile fabrication of ultrathin antibacterial hydrogel films via layer-by-layer 'click' chemistry. Polym. Chem. 2014, 5, 6489-6494. [CrossRef]

15. Zhang, Z.; Du, J.; Li, Y.; Wu, J.; Yu, F.; Chen, Y. An aptamer-patterned hydrogel for the controlled capture and release of proteins via biorthogonal click chemistry and DNA hybridization. J. Mater. Chem. B 2017, 5 , 5974-5982. [CrossRef]

16. Ata, S.; Banerjee, S.L.; Singha, N.K. Polymer nano-hybrid material based on graphene oxide/POSS via surface initiated atom transfer radical polymerization (SI-ATRP): Its application in specialty hydrogel system. Polymer 2016, 103, 46-56. [CrossRef]

17. Shi, J.; Guobao, W.; Chen, H.; Zhong, W.; Qiu, X.; Xing, M.M.Q. Schiff based injectable hydrogel for in situ pH-triggered delivery of doxorubicin for breast tumor treatment. Polym. Chem. 2014, 5, 6180-6189. [CrossRef]

18. Hozumi, T.; Kageyama, T.; Ohta, S.; Fukuda, J.; Ito, T. Injectable Hydrogel with Slow Degradability Composed of Gelatin and Hyaluronic Acid Cross-Linked by Schiff's Base Formation. Biomacromolecules 2018, 19, $288-297$. [CrossRef] [PubMed]

19. Park, M.R.; Seo, B.B.; Song, S.C. Dual ionic interaction system based on polyelectrolyte complex and ionic, injectable, and thermosensitive hydrogel for sustained release of human growth hormone. Biomaterials 2013, 34, 1327-1336. [CrossRef] [PubMed]

20. Mihajlovic, M.; Staropoli, M.; Appavou, M.S.; Wyss, H.M.; Pyckhout-Hintzen, W.; Sijbesma, R.P. Tough Supramolecular Hydrogel Based on Strong Hydrophobic Interactions in a Multiblock Segmented Copolymer. Macromolecules 2017, 50, 3333-3346. [CrossRef] [PubMed]

21. Xing, B.; Yu, C.W.; Chow, K.H.; Ho, P.L.; Fu, D.; Xu, B. Hydrophobic interaction and hydrogen bonding cooperatively confer a vancomycin hydrogel: A potential candidate for biomaterials. J. Am. Chem. Soc. 2002, 124, 14846-14847. [CrossRef] [PubMed]

22. Zou, Y.; Zhang, L.; Yang, L.; Zhu, F.; Ding, M.; Lin, F.; Wang, Z.; Li, Y. 'Click' chemistry in polymeric scaffolds: Bioactive materials for tissue engineering. J. Control. Release 2018, 273, 160-179. [CrossRef] [PubMed]

23. Gandini, A. The furan/maleimide Diels-Alder reaction: A versatile click-unclick tool in macromolecular synthesis. Prog. Polym. Sci. 2013, 38, 1-29. [CrossRef]

24. Koehler, K.C.; Anseth, K.S.; Bowman, C.N. Diels-alder mediated controlled release from a poly(ethylene glycol) based hydrogel. Biomacromolecules 2013, 14, 538-547. [CrossRef] [PubMed]

25. Kirchhof, S.; Strasser, A.; Wittmann, H.; Messmann, V.; Hammer, N.; Goepferich, A.M.; Brandl, F.P. mechanism of Diels-Alder hydrogels. J. Mater. Chem. B Mater. Biol. Med. 2014, 3, 449-457. [CrossRef]

26. Yu, F.; Cao, X.; Du, J.; Wang, G.; Chen, X. Multifunctional Hydrogel with Good Structure Integrity, Self-Healing, and Tissue-Adhesive Property Formed by Combining Diels-Alder Click Reaction and Acylhydrazone Bond. ACS Appl. Mater. Interfaces 2015, 24023-24031. [CrossRef] [PubMed]

27. Yu, F.; Cao, X.; Zeng, L.; Zhang, Q.; Chen, X. An interpenetrating HA/G/CS biomimic hydrogel via Diels-Alder click chemistry for cartilage tissue engineering. Carbohydr. Polym. 2013, 97, 188-195. [CrossRef] [PubMed]

28. Yu, F.; Cao, X.; Li, Y.; Zeng, L.; Zhu, J.; Wang, G.; Chen, X. Diels-Alder crosslinked HA/PEG hydrogels with high elasticity and fatigue resistance for cell encapsulation and articular cartilage tissue repair. Polym. Chem. 2013, 4, 2464. [CrossRef]

29. Yu, F.; Cao, X.; Li, Y.; Chen, X. Diels-Alder Click-Based Hydrogels for Direct Spatiotemporal Postpatterning via Photoclick Chemistry. ACS Macro Lett. 2015, 4, 289-292. [CrossRef]

30. Yu, F.; Cao, X.; Li, Y.; Zeng, L.; Yuan, B.; Chen, X. An injectable hyaluronic acid/PEG hydrogel for cartilage tissue engineering formed by integrating enzymatic crosslinking and Diels-Alder 'click chemistry'. Polym. Chem. 2014, 5, 1082-1090. [CrossRef]

31. Wang, G.; Zhu, J.; Chen, X.; Dong, H.; Li, Q.; Zeng, L.; Cao, X. Alginate based antimicrobial hydrogels formed by integrating Diels-Alder 'click chemistry' and the thiol-ene reaction. RSC Adv. 2018, 8, 11036-11042. [CrossRef]

32. Smith, L.J.; Taimoory, S.M.; Tam, R.Y.; Baker, A.E.G.; Mohammad, N.B.; Trant, J.F.; Shoichet, M. Diels-Alder Click-Crosslinked Hydrogels with Increased Reactivity Enable 3D Cell Encapsulation. Biomacromolecules 2018. [CrossRef] [PubMed] 
33. Wang, L.; Zhou, W.; Wang, Q.; Xu, C.; Tang, Q.; Yang, H. An Injectable, Dual Responsive, and Self-Healing Hydrogel Based on Oxidized Sodium Alginate and Hydrazide-Modified Poly(ethyleneglycol). Molecules 2018, 23, 546. [CrossRef] [PubMed]

34. Wang, J.; Zhang, F.; Tsang, W.P.; Wan, C.; Wu, C. Fabrication of injectable high strength hydrogel based on 4-arm star PEG for cartilage tissue engineering. Biomaterials 2017, 120, 11-21. [CrossRef] [PubMed]

35. Nam, K.; Kimura, T.; Kishida, A. Preparation and characterization of cross-linked collagen-phospholipid polymer hybrid gels. Biomaterials 2007, 28, 1-8. [CrossRef] [PubMed]

36. Tan, R.; She, Z.; Wang, M.; Fang, Z.; Liu, Y.; Feng, Q. Thermo-sensitive alginate-based injectable hydrogel for tissue engineering. Carbohydr. Polym. 2012, 87, 1515-1521. [CrossRef]

37. Lu, M.; Liu, Y.; Huang, Y.C.; Huang, C.J.; Tsai, W.B. Fabrication of photo-crosslinkable glycol chitosan hydrogel as a tissue adhesive. Carbohydr. Polym. 2018, 181, 668-674. [CrossRef] [PubMed]

38. Qi, C.; Liu, J.; Jin, Y.; Xu, L.; Wang, G.; Wang, Z.; Wang, L. Photo-crosslinkable, injectable sericin hydrogel as 3D biomimetic extracellular matrix for minimally invasive repairing cartilage. Biomaterials 2018, 163, 89-104. [CrossRef] [PubMed]

39. He, H.; Adzima, B.; Zhong, M.; Averick, S.; Koepsel, R.; Murata, H.; Russell, A.; Luebke, D.; Takahara, A.; Nulwala, H.; et al. Multifunctional photo-crosslinked polymeric ionic hydrogel films. Polym. Chem. 2014, 5, 2824. [CrossRef]

40. Majima, T.; Schnabel, W.; Weber, W. Phenyl-2,4,6-trimethylbenzoylphosphinates as water-soluble photoinitiators. Generation and reactivity of $\mathrm{O}=\mathrm{P}(\mathrm{C} 6 \mathrm{H} 5)\left(\mathrm{O}^{-}\right)$radical anions. Die Makromol. Chem. 1991, 192, 2307-2315. [CrossRef]

41. Yao, Y.; Wang, Y. ATDC5: An excellent in vitro model cell line for skeletal development. J. Cell. Biochem. 2013, 114, 1223-1229. [CrossRef] [PubMed]

42. Kumar, D.S. Structure and Effect of Pyrolisis on Plasma Polymerized Polyfuran Thin Films. J. Appl. Polym. Sci. 1999, 75, 1176-1179. [CrossRef]

43. González-Tejera, M.J.; de la Blanca, E.S.; Carrillo, I. Polyfuran conducting polymers: Synthesis, properties, and applications. Synth. Met. 2008, 158, 165-189. [CrossRef]

44. Gok, A.; Oksuz, L. Atmospheric Pressure Plasma Deposition of Polyfuran. J. Macromol. Sci. Part A 2007, 44, 1095-1099. [CrossRef] 